\title{
Lessons as a tool to combine flip teaching and transversal skills at the UPV: A pilot experience in soil genesis subjects
}

\author{
Héctor Moreno-Ramóna, Sara Ibáñez-Asensio, Alfonso Martínez García, Ignacio \\ Guillén Guillamón, Marta Cabedo Fabrés, Ana I. Jiménez Belenguer, Salva Calvet \\ Sanz \& Miguel Ferrando Bataller
}

${ }^{\mathrm{a}}$ GRIPAU, Grupo Interdisciplinar para el Aprendizaje Universitario. Universitat Politècnica de València (hecmora@prv.upv.es)

\begin{abstract}
The potential offered by technologies is a reality that must be addressed and used in the Higher Education environments. Professors must be able to integrate technologies into their sessions and facilitate the work of the skill acquisition. The main objectives of this work are: i) to take advantage of the Lessons tool (PoliformaT) to evaluate the acquisition of transversal competences and, ii) to compare if the use of flip teaching improves its acquisition. In the subject of "Geology, Soil science and Climatology" (Degrees in Agri-Food Engineering and Forestry Engineering), an experience was developed during two academic courses in a population of 169 students on average each year. Through Lessons, a template was designed for the student to work, sequentially and based on their knowledge, a specific activity of soil science. In the activity, the student had to face a practical assumption with 4 options to consider as a response. According to its response the specific skills and critical thinking skill would be evaluated. The first year the students had to carry out the activity autonomously in PoliformaT, but in the second year, flip teaching was applied in the same activity. In that occasion; students had to watch online material and subsequently work on the specific concepts in class. Finally, they had to solve independently the practical case in Lessons, where they were evaluated and feedback was provided. The combination of "skill assessment and flip teaching" promoted that in the second year, 66\% of the students acquired an adequate level of critical thinking skill. However, although the first year, $65 \%$ of the students also acquired it, it has been detected that in the second year there was an increase of $7 \%$ of students that passed from good to excellent acquisition level.
\end{abstract}

Keywords: Transversal skills, flip teaching, Lessons, Poliforma, UPV. 
Lessons as a tool to combine flip teaching and transversal skills at the UPV: A pilot experience in soil genesis subjects

\section{Introduction}

Society has undergone a continuous transformation over the past 20 years. The new information and communication technologies cover practically all areas of our lives, and at the same time they are changing our way of doing things at work, leisure, social relations, thinking, and even in our way of learning. It is a reality that the new generations are dominating technologies, so the new digital context cannot be left aside and its role in the training process is key in teaching the future (Lucena, 2005).

Nowadays, the information available on the Internet is enormous, and the skills acquired naturally, since childhood by students are advantages that should be exploited in the learning process. University students can gather information that will help them to build new knowledge, or improve what they have already acquired, reordered, reflected and reasoned, in order to obtain their own conclusions (Bain, 2007).

Therefore, teaching faces itself to a new scenario where the professors' mission has changed. Professor acts as a guide in the learning process, in which the student is the main actor. It has been passed from the master lecture by the teacher(as the only methodology of knowledge acquisition) to a wide range of teaching methodologies where the practical and comprehensive visions allow the learners to seek, select, process and assimilate the information that the professor can provide (Adell, 1997). In that environment, the main problem of students is not where to find the information, if not, where to find quality information, being in this aspect the professor a key figure and guide.

The skills acquired by students before entering university studies should be used for teaching practice. There are many examples that show good results from the application of new technologies in the acquisition and construction of meaningful learning (Gómez, 2014, Brandão et al., 2016, Diego et al., 2016, Esteve, 2016). In all of these studies are reflected a change of roles through the application and use of new technologies, as well as the need for student motivation. The intrinsic motivation of the students and the ease of TIC's use favor that the students remain active and motivated during the learning process, because they are who chooses what and how to learn (Anderson, 2016).

Generously the students feel more motivated when they take part in the learning process. They begin to ask questions such as: Why is this process happening? Which are the causes? How can I improve? How can I solve the problems/questions?. At this moment, they are building a reinforced knowledge. However, the question for professors is usually how to motivate students for their involvement in the learning process.

It is clear that students are motivated when they consider easily overcome a challenge or goal based on their own knowledge, but what about students who do not believe they can achieve that goal? Are they de-motivated? Therefore, should we change the planning 
towards the achievement of less ambitious objectives? The answer is NO. Due to this action, some students can be discouraged by the ease of the objectives.

As professors and guides for the students, the solution is to establish motivating and accessible goals for them. The students have to achieve them with their own effort because this action can motivate them at the same time. In this regard, Lessons (SAKAI web environment 3.0) as a sequencer of learning is an ideal tool. It favors the creation of content itineraries according to the student's own needs. On the other hand, the students use new technologies as a motivating factor. If we join all these aspects and add active methodologies, we will be promoting work environments and the acquisition of current, dynamic and targeted knowledge for each type of student.

There are a lot of experiences developed in blended learning or flip teaching methodologies, where classroom work is combined with online work (Garrison and Vaughan, 2013; Ilic et al., 2013; Jordan et al., 2014, Teo et al., 2014, Stockwell et al., 2015; Fautch, 2015). Those methodologies favor the student's motivation and it produces that students get out of their "comfort zone". Traditional methodology is replaced by a combined teaching-learning system in which the student feels motivated and participates in their progress (Lucena, 2015).

Combining the ideas expressed above, the goal of this study is to test and convey the assessment of transversal skills used through an advanced tool (Lessons) favoring the development and acquisition of skills through the use of active methodologies in soil genesis subjects.

\section{Materials and methods}

The study has been carried out during two years on the subject of Geology, soil science and climatology which is taught in the first course of the degrees of agronomic engineering and forest engineering. Both grades are taught at the School of Agricultural Engineering and Environment belonging to the Universitat Politécnica de Valencia. An amount of 156 (year 2016-2017) 182 students (year 2017-18) have participated in the study. Divided in 4 groups, the students have been evaluated in order to work and develop the skill of critical thinking.

Lesson builder has been the tool selected for working transversal skills. The main advantage of this tool is that allows the inclusion of didactic resources (video lectures, online resources, etc.) in the several itineraries according to the student's own needs. According to the methodology developed, the template was developed and improved with 

genesis subjects

Lessons tool. The template was divided in 3 sections: Introduction, development of the activity and assessment. In the Introduction section, the students were asked about the level of knowledge in the transversal skill (Figure 1). Lessons allows the professor to create an itinerary with several questions that should be replied by the students. According to the answers, the students were redirected to a different parts of the template in order to improve their knowledge. In the case that students did not know anything about critical thinking skill, they were redirected to the institutional webpage about transversal skills in the UPV. On the contrary, if they replied that they knew about critical thinking, they were redirected to another part of the template: Self-evaluation.

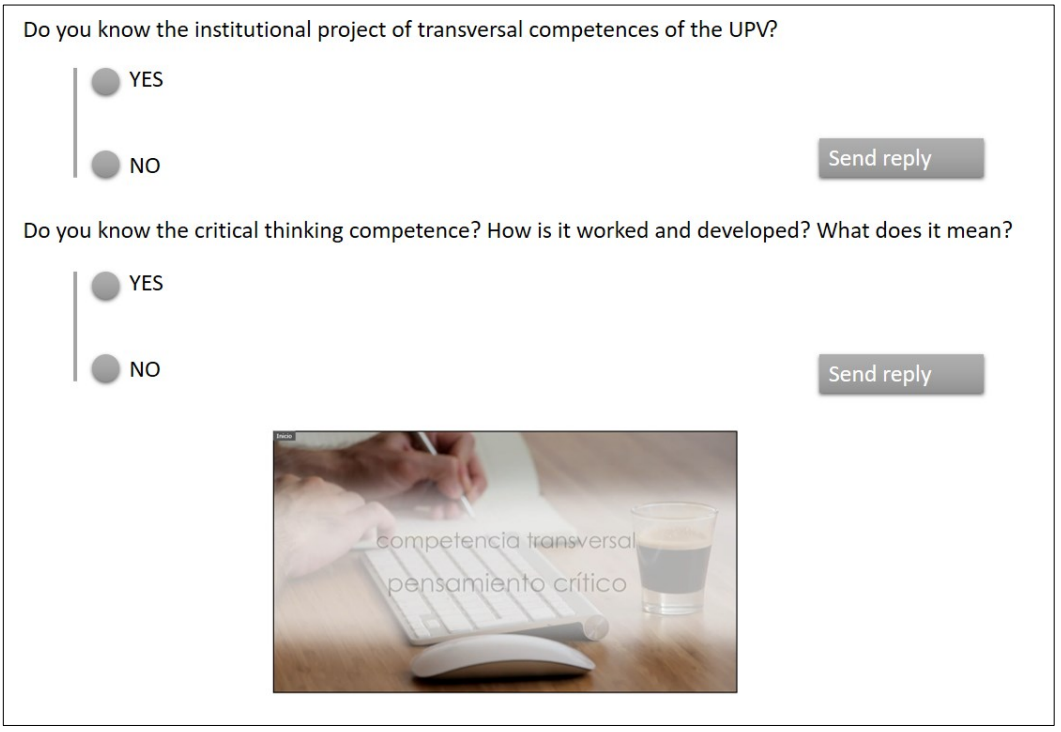

Fig. 1 First section of Lessons template

In the self-evaluation section, four questions were asked to the students to know their initial level in the critical thinking skill. Once time the questions were replied the students have to open a video lecture prepared for completing the activity where the student had to work specific contents of soil genesis and the critical thinking skill.

With the combination of the itineraries created in lessons and video lectures, the knowledge gaps were corrected equitably to the students' own needs. New and active technologies (flip teaching), active students and transversal skills were worked with a template that was adjusted to each student (Figure 2). 


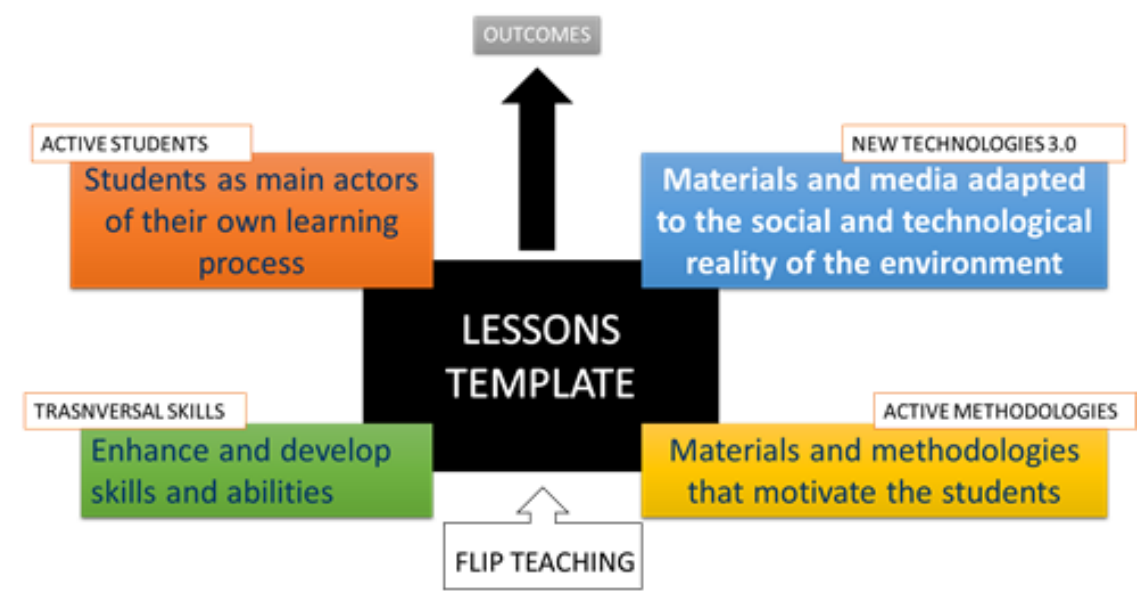

Fig. 2. Workflowchart

Once the activity was done, the students passed to the evaluation section. In that section, the professor evaluated the activity and a feedback between student-professor was produced. In that feedback, the student was informed about the deficiencies and tools to improve and develop the gaps of knowledge.

The outcomes were obtained by comparing the two-year data through surveys and integrated questions in the Lessons tool.

\section{Results}

The first set of questions developed in the template reveals that UPV has been doing an excellent work in order to explain the institutional Project of transversal skills in welcome days, which aim to expose and facilitate the integration of students in the university. 80 percent of the students, on average in both years, knew the institutional Project about transversal skills, with a slightly higher percentage who knew something about the skill that they were going to work on the subject (84\%). That outcome reveals that only $20 \%$ of the students selected the itinerary of "lack of awareness about the skill", in which the student was redirected to online resources where concepts about it were explained.

According to the self-evaluation questions, the students' replies revealed that $94 \%$ and $84 \%$ of students in (year 2016-17 and 2017- 18 respectively), showed a critical attitude to reality. 
Lessons as a tool to combine flip teaching and transversal skills at the UPV: A pilot experience in soil genesis subjects

In the same trend, the students consider that when they read a text, observe any Powerpoint presentation or listen to a lecture, they always detect the inconsistencies or contradictions that occur. More specifically, around $75 \%$ of the students in both years are capable to distinguish and detect the inconsistencies.

Although in general, the students have shown the same trends in both years, the students of 2017-18 showed different behaviour in two self-evaluation questions compared with the students in the first year of the study. Whereas in 2016-17, more that $90 \%$ of the students were capable to differentiate between facts, opinions, interpretations or evaluations, in the second year only $69.6 \%$ of students have developed that ability (Figure 3 ). This outcome showed the same trend of the reliability of the sources and their testing. Only $68.7 \%$ of students in the second year of the students confirmed that they only used reliable sources. That outcome was contradictory with the bibliography used in the activity, because more than $80 \%$ of the students used "Wikipedia" as a source to justify their conclusions. However, it is true that the majority of the students used that source combined with other official or scientific sources with a proven base (articles, institutional reports, etc.)

ABILITY TO DIFFERENTIATE BETWEEN

FACTS, OPINIONS, INTERPRETATIONS OR EVALUATIONS

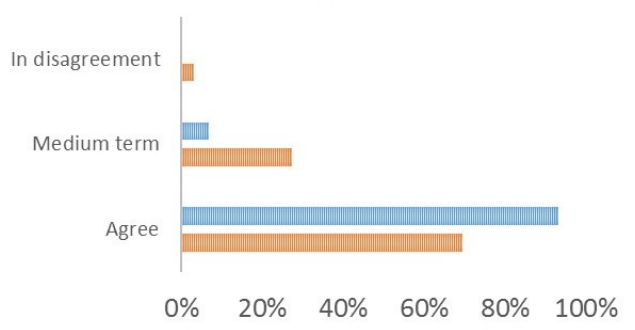

CONTRAST THE INFORMATION IN $100 \%$ RELIABLE SOURCES

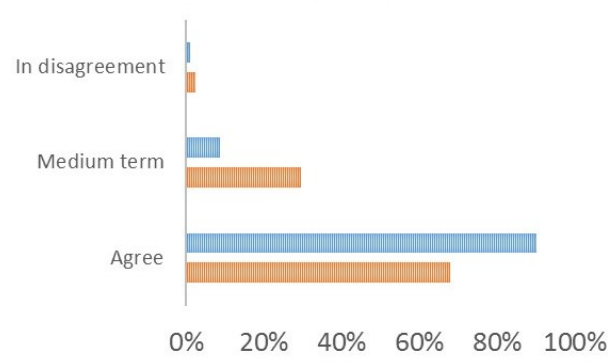

[ 2016-2017 $=2017-2018$

Fig. 3. Self-evaluation replies by students

After carrying out the activity and using the video lectures, $80 \%$ of the students as an average considered that they have a good or excellent level of development of the critical thinking skill. However, only $65.6 \%$ and $66.3 \%$ of the students (in 2016-17 and 2017-18 respectively) reached this status. In addition, although there was only $0.71 \%$ of difference between both years in the skill acquisition, the students who reached the excellence in their qualifications were $7.0 \%$ higher in the second year than the first. It is also necessary to highlight that in the second year, $11.6 \%$ of the students did not reach the level of skill required for a first year of university studies. In the 2016-17 academic year, the percentage of students who did not acquire the critical thinking skill was $4.4 \%, 7.2 \%$ less than the 
second year. This percentage can be attributed to the introduction of online resources (video lectures, etc.), because there are some students who, although they control the new technologies, a priori show a rejection of their use in education.

Finally, note that $78.3 \%$ of students (average of both years) believe that self-assessment is necessary prior to carrying out activities because it encourages self-knowledge of the state of acquisition of the skill. In this sense, $68 \%$ of students on average believe that Lessons is a good content sequencer. However, in that outcome the trend between both years was different. In 2016-17 only 56.5\% believed that Lessons were a good tool for learning purposes, but in 2017-18 the percentage was increased to $81.2 \%$. The improvement in the perception of the second year may be due to the preparation and planning of the entire course on the Lessons platform. In this way, as the course progressed, the contents of each one of the sessions or activities related to the didactic contents were gradually opened. The template used to evaluate the critical thinking skill was introduced within the Lessons planning of the subject, and by this reason, the students considered Lessons as a good sequencer. In the same way, $81.2 \%$ of the students believed that Lessons had facilitated the work and the acquisition of the skill in the second year versus $56.3 \%$ in the first. There was an improvement of $24 \%$ between two years, so the improvements introduced after the first experience caused a significant improvement in the perception of the students.

\section{Conclusions}

As a general conclusion, this study and the work carried out, has facilitated the creation of an effective template for the evaluation of critical thinking skill in soil genesis subjects. Likewise, the students have improved the level of acquisition of the skill and the perception of Lessons as a learning tool. This study and the work carried out has facilitated the creation of an effective template for the evaluation of critical thinking skill in soil genesis subjects. Likewise, the students have improved the level of acquisition of the skill and the perception of Lessons as a learning tool. In addition, with this methodology, they have used online resources that have improved the gaps of knowledge that they showed at the beginning of the action. However, we have to control the increase of people who have not reached the correct skill level.

Finally, through Lessons tool, students have been motivated in the realization and acquisition of skills in general. They have been able to develop the activity prepared for that purpose and they have shown an actively participate in the process of self-evaluation and work development. 
Lessons as a tool to combine flip teaching and transversal skills at the UPV: A pilot experience in soil genesis subjects

\section{References}

Adell, J. (1997) Tendencias en educación en la sociedad de las tecnologías de la información. Revista Electrónica de Tecnología Educativa nº 7 ISSN: 1135-9250.

Anderson, M (2016). Learning to Choose, Choosing to Learn: The Key to Student Motivation and Achievement. Association for Supervision \& Curriculum Development.

Bain, K (2007). Lo que hacen los mejores profesores universitarios.Valencia. Servei de publicacions Universitat de València

Brandão, D., Vargas, A., Frances, P., Cobo, C., Valentim, G., Jara, I., Lugo, M.T., Ruiz, V. (2016) Experiencias evaluativas de tecnologías digitales en la educación. São Paulo. Fundación telefónica.

Esteve, F. (2016). Bolonia y las TIC: de la docencia 1.0 al aprendizaje 2.0 La Cuestión Universitaria 5: 58-67.

Fautch, J. (2015). The flipped classroom for teaching organic chemistry in small classes: is it effective?.Chemistry Education Research and Practice,16(1): 179-186.

Garrison, R., Vaughan, N. (2013) Institutional change and leadership associated with blended learning innovation: Two case studies, Higher Education, Volume 18: 24-28,

Gómez Galán, J (2014). El fenómeno MOOC y la universalidad de la cultura: las nuevas fronteras de la educación superior. Profesorado. Revista de Currículum y Formación de Profesorado,18 (1): $74-91$

Ilic, D., Nordin, R., Glasziou, P., Tilson, J., Villanueva, E. (2013) Implementation of a blended learning approach to teaching evidence based practice: a protocol for a mixed methods study. BMC medical education, 13(1), 170.

Jordan, C., Pérez, M.J., Sanabria, E., (2014). Investigación del impacto en un aula de matemáticas al utilizar flip edication. Pensamiento matemático (2):9-22

Lucena, I.V. (2015). La aplicación de las TIC y la evaluación por competencias en el Grado de Derecho. International journal of educational research and innovation, 5: 42-54

Diego, P., Mora, M., Cuadros, R., (2016). La importancia de las nuevas tecnologías en el proceso educativo. Propuesta didáctica TIC para ELE Revista Fuentes 18..2: 209-223.

Stockwell, B., Stockwell, M., Cennamo, M., Jiang, E. (2015) Blended Learning Improves Science Education, Cell, Volume 162, Issue 5, 27: 933-936,

Teo, T., Tan, K., Yan Y., Teo, Y., Yeo, L. (2014). How flip teaching supports undergraduate chemistry laboratory learning.Chemistry Education Research and Practice 15(4), 550-567. 